\title{
The Fortification Tempeh of Rice Bran Chitosan as Functional Food Antihypercholesterolemia in Indonesia
}

\author{
Agnes Sri Harti, Anis Nurhidayati, Desy Handayani, Estuningsih, Heni Nur Kusumawati, and Dwi Susi \\ Haryati
}

\begin{abstract}
Tempeh is a traditional Indonesian fermented food that use raw materials of yellow soy beans by Rhyzopus oryzae. The concept of food fortification can be used to characterize food biosuplemen health improvement as a functional food. Tempeh of rice bran chitosan is one form of food fortification using soy beans and rice bran as raw material.

The use of soybean seeds with a mixture of rice bran provides an alternative dependence soybean imports in Indonesia. The result showed that the mixture composition of soybean: rice bran $=2$ : 1 and chitosan $2 \% \mathrm{w} / \mathrm{w}$ can be used as functional food to provide anti-hypercholesterolemic effect.
\end{abstract}

Index Terms - Antihypercholesterolemia, chitosan, rice bran, tempeh.

\section{INTRODUCTION}

Tempeh has been known as a functional food with raw materials through fermentation of yellow soybean by fungus Rhizopus sp is $R$. oryzae, $R$. stolonifer, $R$. oligosporus. Tempeh is known as the food preferred by all ages and has many kinds of processed food with based ingredients tempeh [1]. Prebiotics are non-digestible food ingredients that could provide beneficial effects for the host. It is able to stimulate the growth of colonic bacteria by increasing the number and activity of probiotics [2], [3]. Number of probiotics can be increased by using more prebiotics. Several classes of polysaccharides resistant, fiber, oligosaccharides, sugar alcohol and chitosan are all known as prebiotics. Chitosan and chito-oligosaccharide which can be obtained from waste of shrimp or crab shells, which are potential and abundant in Indonesia, as a prebiotic natural source [4]-[7].

Rice bran as a by-product of rice milling karyopsis obtained from the outer layer of rice, have bioactive components oryzanol, tocopherol, and ferulic acid which have the function to lowering cholesterol and improving defecation. Rice milling process produces a $10 \%$ of by-product of rice bran. In Indonesia, the amount of bran

Manuscript received March 2, 2014; revised May 13, 2014. This work was supported in part by the Directorate General of Higher Education Indonesia for supporting this research work under 2th Fundamental grants 2014

Agnes Sri Harti and Dwi Susi Haryati are with the Departement of Nursing, Kusuma Husada Surakarta Institute Health of Science, Surakarta Central of Java Indonesia, Indonesia (e-mail: agnessriharti@yahoo.com, susisimiliqyti@yahoo.com).

Anis Nurhidayati and Desy Handayani are with the Departement of Midwifery, Kusuma Husada Surakarta Institute Health of Science, Surakarta Central of Java Indonesia, Indonesia (e-mail: abila_salsa@yahoo.com, ecy_han@yahoo.co.id).

Estuningsih and Heni Nur Kusumawati are with the Departemen of Acupuncture, Surakarta Health Polytechnic, Indonesia (e-mail: debora_estu@yahoo.com, heninurkusumawati@yahoo.com). production is estimated at 4-6 million tons per year [8], [9].

Traditionally, yellow-seeded soybeans are usually preferred as the raw material on tempeh production. Dependence on imported soybean production can lead to high cost of raw materials, which affects the production of tempeh with increasing need of soybean, therefore looking for potentially alternative raw materials as the substrate is very important. The concept of food fortification lately used for the characterization of foods biosuplemen health improvement as a functional food. Therefore efforts should be done to substitute the yellow soybean seeds by using other raw materials that are safe, nutritious and economical. Optimization of probiotics can be done by selecting the appropriate strains or selection, the selection of alternative substrates includes bran and chitosan [10], [11].

Rice bran and chitosan have been added to the tempeh of rice bran chitosan, as the food fortification based on fermented soy beans. Therefore, one form of novelty can be developed as a functional food. Under these conditions, the purpose of the fortification tempeh of rice bran chitosan as a biosuplemen prebiotic natural healthy food for functional food to provide antihypercholesterolemia is effect in Indonesia.

\section{MATERIAL AND METHODS}

\section{A. Isolation Rhizopus sp}

The powdered inoculum of Rhizopus $s p$ was inoculated to the media Sabaraud Glucose Agar, and incubated at room temperature. Identification of Rhizopus $s p$ was based on microscopic examination of morphology.

\section{B. Syntesis of Chitosan and Rice Bran}

The method of synthesize chito-oligosaccharide from crab shell waste and shrimp shells is deacetylation of chitin. Sampling from shrimp shell and crab shell, were washed with water and dried for two days. Waste shells of shrimp, with crab were ground into flour particle with the size from 1.77 to $3.25 \mathrm{~mm}$. Then performed the demineralization by adding $1 \mathrm{~N}$ $\mathrm{HCl}$ with ratio $1: 7$ while heated $90^{\circ} \mathrm{C}$ for one hour. Mixture was decanted, and washed again until neutral $\mathrm{pH}$ and dried. Performed after the deproteination with the addition of $3.5 \%$ $\mathrm{NaOH}$ solution ratio of 1: 10 and then heated at $90^{\circ} \mathrm{C}$ for one hour. After it cooled, decanted again, washed with water until neutral $\mathrm{pH}$, and then dried. Bleaching with the addition of $2 \%$ $\mathrm{H}_{2} \mathrm{O}_{2}$ ratio 1: 10 in order to obtain a white powdery chitin. Production of chitosan or chito-oligosaccharide was done by deacetylation of chitin flour with the addition of $50 \% \mathrm{NaOH}$ solution, and then heated at a temperature of $80^{\circ} \mathrm{C}$ for one hour [12], [13]. 
Synthesis of rice bran was obtained from outer layer and karyopsis of rice milling.

\section{The Synergistic Effect of Synbiotic in Vitro}

Isolation of LAB (Lactic Acid Bacteria) were used from industrial fermentation products. Chitosan and rice bran from synthesized and then used as prebiotic. BHI liquid medium is added with prebiotics (chitosan, rice bran) and probiotics isolates inoculated $(10 \% \mathrm{v} / \mathrm{v})$ then incubated at $37^{\circ} \mathrm{C}$ for 20 hours. The growth of probotic cells in liquid media was measured of turbidity.

\section{Fermentation Tempeh of Rice Bran Chitosan}

Soy beans were first soaked in water for 12-15 hours. Then the soy beans were steamed for 15 minutes. The cooked soy beans were cooled to room temperature, and thoroughly mixed with rice bran at a ratio of $2: 1$. Then, inoculum powder of Rhizopus sp was inoculated at $0,1 \%$ of the cooked soybeans with chitosan $2 \% \mathrm{w} / \mathrm{w}$ and spread evently onto the mixture soybeans and rice bran. They were placed on plastic bag and kept incubated at temperature of $30^{\circ} \mathrm{C}$ for $24-36$ hours.

\section{E. Analytical Methods}

Analyze of product fermentation includes the measurement level of fat and protein and microbiological. The organoleptic was measured with Hedonic test preference level (color, smell, consistency, flavor) by panelists.

\section{RESULT AND DisCUSION}

\section{A. Syntesis of Chitosan and Rice Bran}
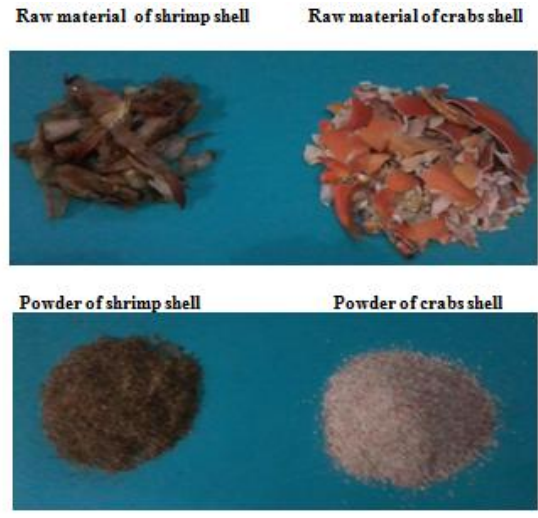

Fig. 1. Raw material of chitosan.
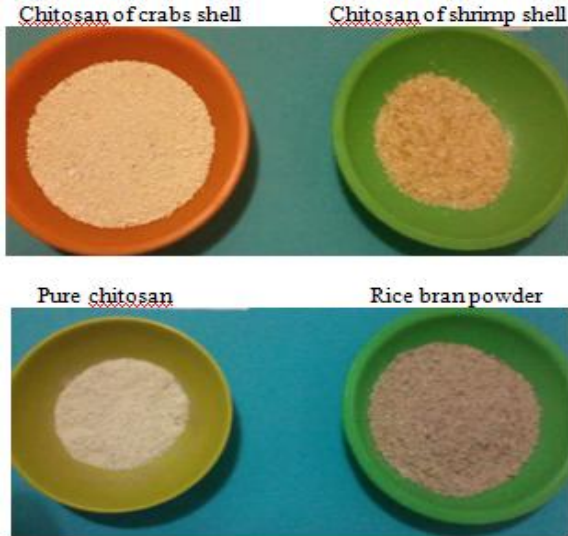

Fig. 2. Product of chitosan and rice bran.
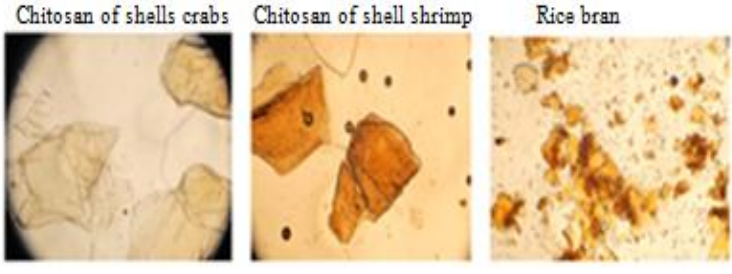

Fig. 3. Microscopic of chitosan from shells of crabs and shrimp, rice bran.

Chitin can be obtained through a two-stage process of deproteination and demineralization from fishery waste materials such as shrimp heads, shells of crabs and other marine animals in Fig. 1 and Fig. 2 [14]. Chitosan has a unique character of adsorbent (see Fig. 3) that is capable of protecting polycationic protein and reduce the rate of growth of pathogenic bacteria. Chitosan can reduce the amount of coliform bacteria and the concentration of iron in well water. Chito-Oligosaccharida (COS), a group of complex compounds gliko-binding protein that has a 1,4-b-glucosamine, which is a derivative of chitosan deacetylation of chitin. The effect of chitooligosakarida as antimicrobial activity is highly dependent on the degree of deacetylation and polymerization of the types of bacteria and fungi. COS as a potential material as 'alternative antibiotics' has a value of more secure without causing residue [15], [16].

Rice bran can be obtained as much as 10 percent from the rice mill, which consists of the aleurone layer of rice (rice kernel), endosperm, and germ as well as carbohydrates, proteins, minerals, fats, vitamin B complex, inositol, phytate, ferulic acid, gamma orizanol, phytosterols, tocotrienols, amino acids, unsaturated fatty acids, and fiber. Rice bran has been used as the cattle feed. Not many people know that the outer layer of rice paddy milling results contain the bioactive components of food that are beneficial to health. However, on the other hand the wealth of nutritional value also has a negative side, the rate of damage occurs, for example, the rice bran will be easily rancid as a result of the decomposition of fats into simpler components such as fatty acids and peroxide because the lipase is abundant in the bran and groats.

\section{B. The Synergistic Effect of Synbiotic}

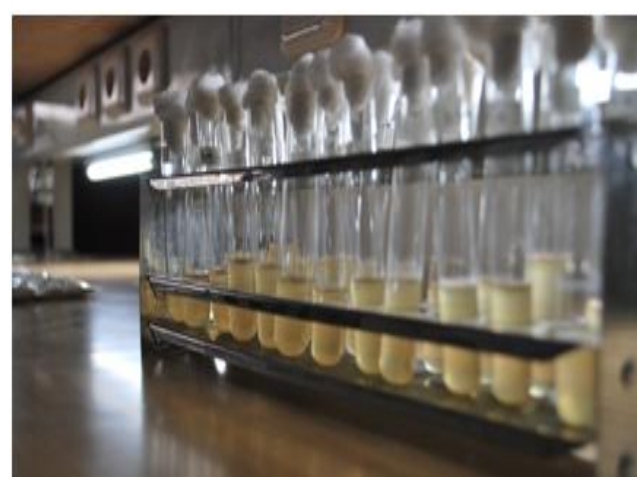

Fig. 4. The probiotic growth in BHI medium.

The measurement results of the in vitro growth of probiotics in liquid BHI media showed that the chitosan from shrimp shells, crab shells and rice bran can increase significantly the growth of probiotics in Fig. 4. Several types of prebiotics are able to be used such as lacto sucrose, soybean oligosacharida, palatinose, isomaltive oligosaccharida, gluco-oligosacharida, xylo oligosacharida, 
lactulose, lactitol and xylitol, sorbitol and mannitol. Several groups including prebiotic substrate are starch (cellulose, hemicellulose, lignin) which are not soluble in water, fiber, oligosaccharides and sugar alcohol [17].

TABLE I: THE GROWTH OF PROBIOTIC IN BHI MEDIUM

\begin{tabular}{lc}
\hline \hline Treatment & Absorbance \\
\hline 1. $\mathrm{BHI}(\mathrm{Control})$ & 0,719 \\
2. $\mathrm{BHI}+2 \%$ chitosan of shrimp & 1,615 \\
3. $\mathrm{BHI}+2 \%$ chitosan of crab & 1,926 \\
4. $\mathrm{BHI}+2 \%$ chitosan of laboratory & 1,473 \\
5. $\mathrm{BHI}+2 \%$ rice bran & 1,804 \\
6. $\mathrm{BHI}+2 \%$ chitosan of shrimp + rice bran & 1,803 \\
7. $\mathrm{BHI}+2 \%$ chitosan of crab + rice bran & 1,833 \\
\hline \hline
\end{tabular}

Rice bran contains bioactive components such as oryzanol, tocopherol, and acids that make felurat potential functional food ingredients. Oryzanol cholesterol has lowering function. Tocopherol is vitamin E, which is an antioxidants. While felurat acid is known to reduce the level of sugar and blood pressure.

\section{Analysis Product of Tempeh of Rice Bran Chitosan}

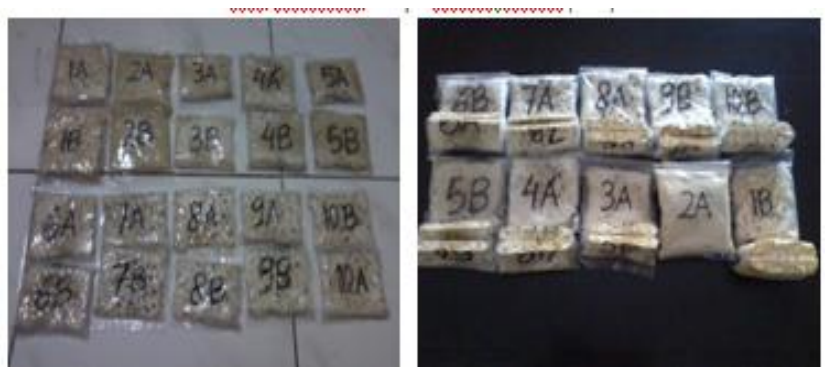

Fig. 5. Product tempeh of rice bran and chitosan.

TABLE II: ANALYSIS OF PRODUCT FERMENTATION

\begin{tabular}{lllcc}
\hline \hline Raw material & $\begin{array}{l}\text { Level } \\
\text { protein } \\
(\% \mathrm{w} / \mathrm{w})\end{array}$ & $\begin{array}{l}\text { Level fat } \\
(\% \mathrm{w} / \mathrm{w})\end{array}$ & E. coli & Salmonella \\
\hline Soy bean & 1.83 & 4.80 & - & - \\
Rice bran & 0.99 & 1.58 & - & - \\
Soy bean : rice bran $(2: 1)$ & & & & - \\
with 2\% COS shrimp shell & 1.24 & 3.80 & - & - \\
with 2\% COS scrab shell & 1.31 & 4.26 & - & - \\
with 2\% chitosan & 1.07 & 4.24 & - & - \\
with 2\% FOS & 1.37 & 4.23 & - & - \\
with 2\% Maltodextrin & 1.09 & 3.95 & - & - \\
\hline \hline
\end{tabular}

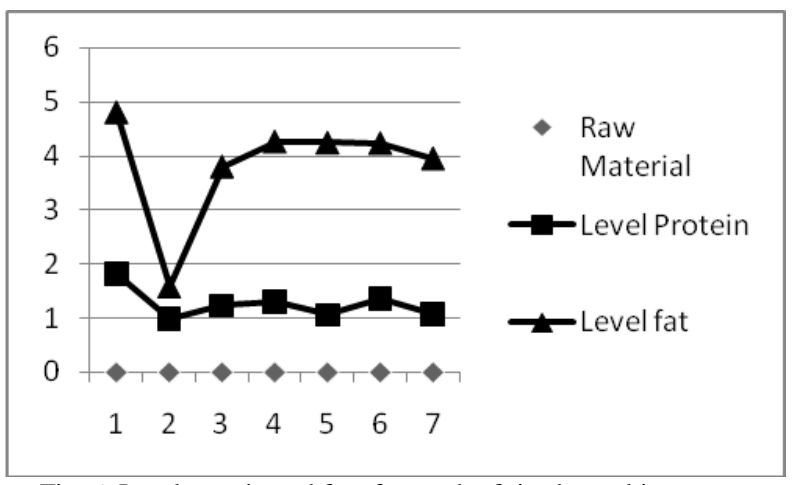

Fig. 6. Level protein and fat of tempeh of rice bran chitosan.

The studies show that rice bran and chito-oligosaccharide are potentially as natural prebiotic on tempe fermented. The mixure soy bean with rice bran at ratio $2: 1$ provides the best organoleptic results. The use of soybean seeds with a mixture of rice bran provides an alternative dependence of imported yellow-seeded soybeans in Indonesia. The fermentation process using soybean rice bran and chitosan improves digestibility value by reduction anti-nutrition factor as tannin and phytase in addition to production of acids which inhibit the production of pathogenic microbes and is particularly important to the manufacture of food designated for special targeted such as infants and aged ones. This shows the rice bran chito-oligosaccharide tempe fermentation process by using Rhizopus sp inoculums can supply higher digestibility value since Rhizopus sp secretes various extracellular enzymes e.g. protease, amylase, and lipase that hydrolyze macromolecule substrate in soybean and rice bran monomer or simpler compound that as a result can be absorbed and synthesised by the body more easily. Soy beans and rice bran can be used as a growth substrate Rhizopus oligosporus. Tempeh of rice bran chitosan indicated is not affecting the consistency and smell. A flavor is influenced by the level of rice bran fiber.

The soybean carbohydrates in tempeh becomes more digestible as a result of the fermentation process. The fermentation process also reduces the phytic acid in soy, which in turn allows the body to absorb the minerals that soy provides. The zygomycete Rhizopus oligosporus is traditionally used to ferment soybean tempe, but it is also possible to ferment other legumes and cereals to tempe. Lactic acid bacteria (LAB) have positive effects on the safety of soybean tempe, but the effects of combination LAB and $R$. oligosporus growth have not been investigated. Four LAB species, Lactobacillus plantarum, Lactobacillus fermentum, Lactobacillus reuteri and Lactococcus lactis were assessed for their growth abilities and their effects on $R$. oligosporus growth during barley tempe fermentation.

The organoleptic test on rice bran chito-oligosaccharide shows addition of rice bran and chito-oligosaccharide does not effect texture and smell, while preference level is subjective to rice bran fibre in Fig. 5-Fig. 7. This can be overcome by sieving rice bran more finely that better rice bran tempe texture is obtained.

The microbiological test on the sample indicated the negative of Escherichia coli and Salmonella sp. Rhizopus oligosporus was secrete a variety of extracellular enzymes are protease, amylase and lipase which can hydrolyze macromolecular substrates in soybean seeds and rice bran into simpler compounds or monomers that more easily absorbed and synthesized in the body. Additionally biopreparation of synbiotic in yogurt provides a synergistic effect as lowering cholesterol levels in vitro and vivo. Probiotics and prebiotics (mixture maltodextrin 2\% and Fruktooligosaccharida 2\% (1:1) was able to suppress the growth of pathogenic Escherichia coli.

\section{Analysis of Cholesterol Levels Tempe Bran Chitosan}

The results showed the addition of chitotosan and rice bran can reduced cholesterol levels in vivo. Under these conditions, chitosan and probiotics can serve for the prevention of hypercholesterolemia. The mechanism of chitosan as an anti-hypercholesterolemia associated chitosan role in carbohydrate metabolism and the role of chitosan as 
bioadsorben very effective especially as microparticles with high porosity properties so as to bind macromolecular compounds such as fats. While the addition of probiotics is expected to provide a synergistic effect between probiotics (Lactic Acid Bacteria) and chitosan as a natural prebiotic derived from crab shell waste. Mechanism Lactic Acid Bacteria in lowering serum cholesterol levels associated with the ability to produce bile salt dehydrogenase enzymes that a role plays in the metabolism of cholesterol [18]-[21].

\begin{tabular}{lc}
\multicolumn{1}{c}{ TABLE III: ANALYSIS OF CHOLESTEROL LEVELS } \\
\hline \hline \multicolumn{1}{c}{ Treatment } & $\begin{array}{c}\text { Cholesterol level } \\
(\mathrm{mg} / \mathrm{dL})\end{array}$ \\
\hline 1. Negative control (feed) & 81,7 \\
2. Positive control (feed + fat) & 185,3 \\
Feed + fat + bran + : & \\
3. 2\% chitosan of shrimp & 103,3 \\
4. 2\% chitosan of crab & 114,0 \\
5. 2\% chitosan laboratory & 97,3 \\
6. 2\% chitosan of crab and probiotic & 106,3 \\
7. 2\% FOS (Fructo-oligosacharide) & 103,3 \\
8. 2\% Maltodextrin & 122,3 \\
\hline \hline
\end{tabular}

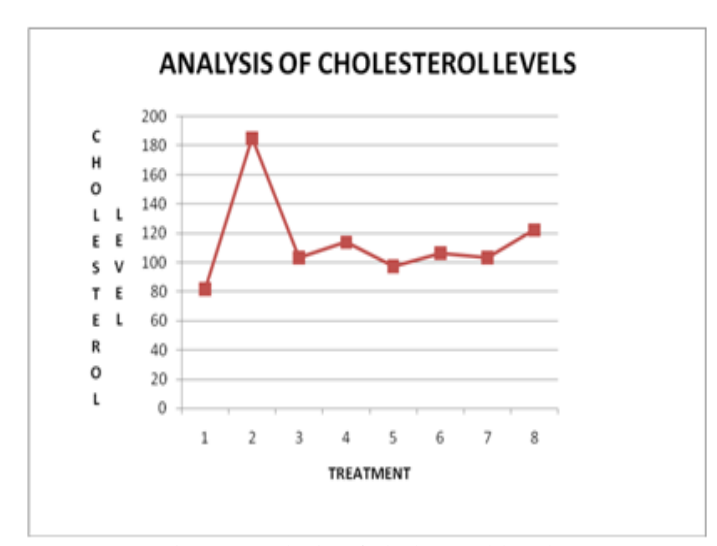

Fig. 7. Analysis of cholesterol levels.

Chitosan widely chito-oligosaccharida as prebiotic oligosaccharides can be used as the substrate for growth of probiotics. Chitosan is able to absorb the fat so that can lower cholesterol. Chito-oligosaccharide showed antibacterial activity, antimetastatic, antiurichemic, antisteoporotic, immunoadjuvant and biocompatibility in vitro. Probiotics and prebiotics (Maltodextrin $2 \%$ and Fructooligosaccharide 2\%) are called synbiotic were able to suppress the growth of pathogenic Escherichia coli. Chito-oligosaccharide from fishery waste can be used as a natural prebiotic. Additionally biopreparation synbiotic in yoghurt provides a synergistic effect lowering cholesterol levels in vitro and vivo [22]-[26].

Hipocholesterolemia effects rice bran and some fractions, has been widely observed both in experimental animals and humans. Rice bran oil significantly reduce blood cholesterol levels, LDL (Low-density lipoprotein) cholesterol, VLDL (Low-density lipoprotein) cholesterol, and can increase blood levels of HDL (High-density lipoprotein) cholesterol. Ability of rice bran oil lowers cholesterol levels due to the oryzanol and other capabilities of materials that are not saponified. Other studies have shown that ferulic acid also plays a role in lowering blood pressure and blood glucose testing both animals and humans. Rice bran can increase the production of erythromycin from culture Saccharopolyspora erythraea

\section{ATCC 11635 [27].}

\section{CONCLUSION}

Fortification tempeh of rice bran chitosan has potential as the functional food antihypercholesterolemia synbiotic in Indonesia.

\section{REFERENCES}

[1] B. Dinesh, R. Bhakyaraj, and R. Vidhayalakshmi. "A low cost nutritious food 'Tempeh'," World Journal of Dairy \& Food Sciences, vol. 4, no. 1, pp. 22-27, 2009.

[2] A. Bomba, R. Nemcova et al., "Improvement of the probiotic their effect of microorganism by combination with maltodextrins, fructo-oligosaccharides and polyunsaturated fatty acid," British Journal of Nutrition, vol. 88, September 2002.

[3] K. K. Buddington, J. B. Donahoo, and R. K. Buddington, "Dietary oligofructose and inulin protect mice from enteric and systemic pathogens and tumor inducers," Journal of Nutrition, vol. 132, pp. 472-477, 2002.

[4] A. S. Harti, A. Nurhidayati, and D. Handayani, "The Potential of rice bran and chito-oligosaccharide as natural prebiotic on traditional tempe in Indonesia," International Journal of Bioscience, Biochemistry and Bioinformatics (IJBBB), vol. 3, no. 6, November 2013, pp. 654-656.

[5] A. S. Harti, Y. Suhartinah, and J. Wiharjo, "Biopreparation Chito-oligosaccharide (COS) of waste fishing experience as a source of prebiotics in functional food," Applied Research Report, Funded by the Central Java Provincial Education Department, 2010.

[6] A. S. Harti, "Biopreparation synbiotic (Probiotics and Prebiotics) in yoghurt as Immunostimulants and lowering cholesterol," Research Report Competitive Research Grant Program based on National Priority Batch I, 2009.

[7] A. S. Harti, "Synergistic effects assessment probiotics with prebiotics to diaregenic Escherichia coli," Young Lecturer Research Report, Funded by the Directorate General of Higher Education, 2007.

[8] K. Ardiansyah et al., "Crude rice bran diet decreases blood pressure in stroke-prone spontaneously hypertensive rats," presented at the JSBBA 2005 Annual Meeting (Japan Society for Bioscience, Biotechnology, and Agrochemistry), Sapporo-Hokkaido, March 28-30, 2005

[9] D. T. Artini, "Sugar production and reduction of substrate rice bran by Rhizopus oryzae," Journal of Biotechnology, vol. 2, no. 1, 2005.

[10] H. J. Choi, J. Ahn, N. C. Kim, and H. S. Kwak, "The effects of microencapsulated chitooligosaccharide on physical and sensory properties of the milk," Asian-Australasian Journal of Animal Sciences, vol. 19, no. 9, pp. 1347-1353, 2006.

[11] P. K. Dutta, J. Dutta, M. C. Chattopadhyaya, and V. S. Tripathi, "Chitin and chitosan: Novel biomaterials waiting for future development," Journal of Polymer Materials, vol. 21, no. 3, pp. 321-333, 2004.

[12] N. Kazami, S. Yasusato et al., "Preparation of Chito-oligosaccharides by Two Step Hydrolysis," Journal Title: Chitin and Chitosan Research, vol. 11, no. 2, pp. 170-171, 2005.

[13] Mirzah, "Improving the quality of shrimp waste meal nutritional value through processing with steam heat," Research Journal of Andalas, vol. 26, pp. 7-12, 1998.

[14] E. Rochima, "Characterization of chitin and chitosan origin waste rajungan Cirebon in West Java," Article Publication Research, Faculty of IPB, 2005.

[15] P. Suptijah, H. Sumaryanto, S. Purwaningsih, and J. Santosa, "The effect of various methods of isolation of chitin and chitosan from shrimp shells to the levels andquality," The Final Report of Research, Faperikan, IPB, Bogor, 1992.

[16] Kaban, "Chemical modification of chitosan and application of products in organic chemistry," Ph.D. dissertation, Faculty of Science, University of North Sumatra, January 24, 2009.

[17] S.-B. Lin et al., "Preparation of antibacterial chito-oligosaccharide by altering the degree of deacetylation of $\beta$-chitosan in a Trichoderma harzianum chitinase-hydrolysing process," Journal of the Science of Food and Agriculture, vol. 89, no. 2, pp. 238-244, January 2009.

[18] M. T. Liong and N. P. Shah, "Acid and bile tolerance and cholesterol removal ability of lactobacilli strains," Journal of Dairy Science, vol. 88 , pp. 55-66, 2005. 
[19] M. T. Liong and N. P. Shah, "Bile salt deconjugation ability, bile salt hydrolase activity and cholesterol co-precipitation ability of lactobacilli strains," Int. Dairy Journal, vol. 15, pp. 391-398, 2005.

[20] M. T. Liong and N. P. Shah, "Optimization of growth of Lactobacillus caseiASCC 292 and production of organic acids in the presence of fructo oligosaccharide and maltodextrin," Journal Food Science, vol. 70, pp. M113-M120, 2005.

[21] M. T. Liong and N. P. Shah, "Optimization of cholesterol removal by probiotics in presence of prebiotics using response surface methodology," Applied. Environment Microbiolology, vol. 71, pp. 1745-175, 2005.

[22] H. Puspita and S. H. Agnes, "Synthesis of Chito-oligosaccharide (COS) from waste shrimp and crab as well as the Natural Resources Prebiotics Sinbiotik In vitro effects," Final Report of Student Creativity Research Program, Funded by the Directorate of Research and Community Services, the Directorate General of Higher Education Ministry of National Education in 2010.

[23] Y. Chen, Y. Chung, L. Wang, K. Chen, and S. Li, "Antibacterial properties of chitosan in waterborne pathogens," Journal of Environmental Science and Health, vol. A37, no. 7, pp. 1379-1390, 2002.

[24] Y. Wang et al., "Antimicrobial effect of Chito-oligosaccharides produced by chitosanase from Pseudomonas CUY8," Asia Pacific Journal of Clinical Nutrition, vol. 16, Suppl 1, pp. 174-177, 2007.
[25] Y. B. Shen et al., "Effects of chito-oligosaccharide supplementation on growth performance, nutrient Digestibility, intestinal morphology, and fecal shedding of Escherichia coli and Lactobacillus in weaning pigs," Journal of Animal Science, vol. 86, pp. 2609-2618, 2008.

[26] C. Joao et al., "Anti-inflammatory activity of chitooligosaccharides in vivo," Marine Drugs, vol. 8, pp. 1763-1768, ISSN 1660-3397, March 2010.

[27] E. R. Nugraheni, S. S. Retno, and A. J. Umar, "Utilization of rice bran to increase the production of erythromycin from culture Saccharopolyspora erythraea ATCC 11635," Journal: Science and Sibernatika, vol. XVII, no. 3, 2004.

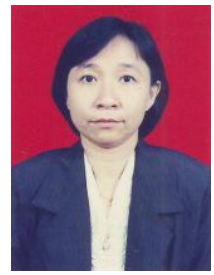

Agnes Sri Harti was born on August 9, 1960 in Semarang Central Java Indonesia. She was a pos graduate of Biology Satya Wacana, Christian University in 1984 and master of biotechnology at the Gadjah Mada University in 2006

Agnes Sri Harti is a lecturer at Kusuma Husada Surakarta Institute of Health Science. Agnes Sri Harti is a lecturer of course basic biology, medical biology, biochemistry, microbiology and parasitology at the Diploma, S-1, D-IV Program of Nursing, Midwifery and Acupuncture.

She is a researcher of the Grant of the Directorate General of Higher Education, Research Lecturer Young, Fundamental, the National Strategy and the Education Department of Central Java. 